\title{
Reflections on a Collaborative, Cross-University National Call for Speech and Language Therapy Placements during the COVID-19 Pandemic
}

\author{
*Kerrie O'Grady ${ }^{a}$, Laura Loftus ${ }^{b}$, Francoise Kielyc $^{c} \&$ Duana Quigley ${ }^{\prime}$ \\ a: University College Cork, Ireland; b: National University of Ireland, Galway, Ireland; \\ c: University of Limerick, Ireland; $d$ : Trinity College Dublin, Ireland
}

\section{Background}

This reflection was written by the four Practice Education Coordinators (PECs) in Speech and Language Therapy (SLT) in the Republic of Ireland (ROI). We have adopted Gibbs' reflective cycle (1998) to structure this reflection (Figure 1). We have specifically chosen this reflective tool as it incorporates feelings and an action plan in the reflection. We believed this was important to capture as this initiative was the result of a crisis and will impact future decisions.

\section{Figure 1}

\section{Gibbs' reflective cycle (1998)}
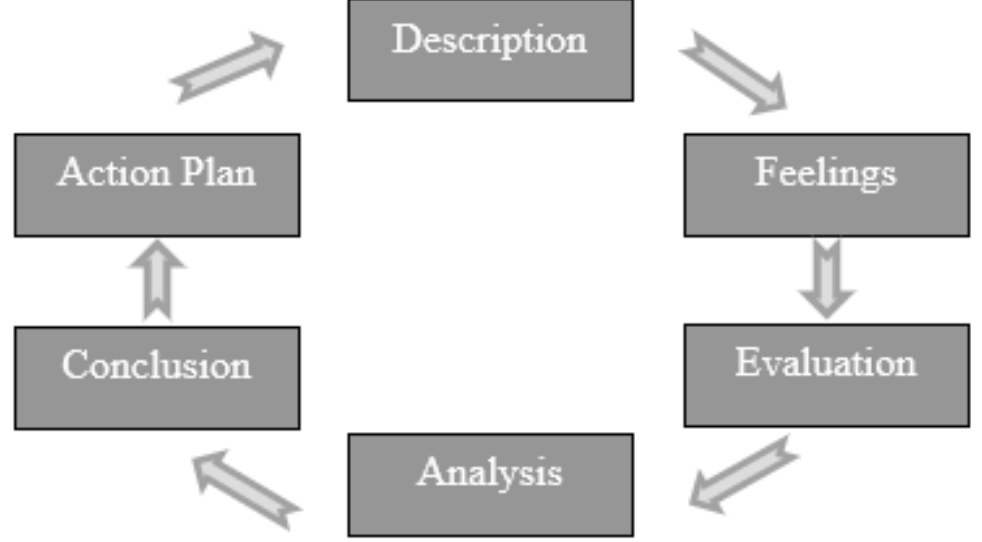

Analysis

Adapted from Learning by Doing: A Guide to Teaching and Learning Methods by G. Gibbs (1998), p. 50. Copyright CC BY-NC https://thoughtsmostlyaboutlearning.files.wordpress.com/2015/12/learning-by-doing-graham-gibbs.pdf

*Corresponding Author: Kerrie O’Grady, Department of Speech and Hearing Sciences, University College Cork, College Road, Cork T12 K8AF Ireland.

Journal URL: https://publications.coventry.ac.uk/index.php/pblh

O’Grady, K., Loftus, L., Kiely, F., \& Quigley, D. (2021). Reflections on a collaborative, cross-university national call for speech and language therapy placements during the COVID-19 pandemic. International Journal of Practicebased Learning in Health and Social Care, 9(2), 78-81. DOI 10.18552/ijpblhsc.v9i2.721

\section{(c) $(1) \odot$}

BY NC ND (C) 2021 Kerrie O’Grady, Laura Loftus, Francoise Kiely, and Duana Quigley. This Open Access article is distributed under the terms of the Creative Commons Attribution Attribution-Non-Commercial No Derivatives 4.0 International License (https://creativecommons.org/licenses/by-nc-nd/4.0/), which permits unrestricted non-commercial use, distribution, and reproduction in any medium, provided the original work is properly cited and is unaltered. 


\section{Reflections}

\section{Stage 1: Description}

SLT education in the ROI takes place in four universities (i.e., University College Cork, Trinity College Dublin, National University of Ireland, Galway, and the University of Limerick) and may be completed at undergraduate or postgraduate level (Quigley et al., 2020). Placements are a central component of each programme, supporting students to integrate theory with practice and develop discipline-specific clinical and professional competencies (McAllister \& Nagarajan, 2015).

As the PECs for our universities, we have responsibility for preparing students and Clinical Educators (CEs) for placements and for securing and organizing high quality placements. Pre-COVID-19, we independently sought placements for our own student cohorts. In ROI, supporting student education is specified as a role of all publicly funded SLT posts, but there are no service level agreements and there is no onus for SLTs to prioritize student learning as part of their workload. This has led to multiple challenges in terms of securing sufficient placements, which is a challenge recognised internationally (Bourne et al., 2019). Similar to many of our colleagues in the United Kingdom and Australia, we are reliant on the goodwill of SLTs to offer students placements (Royal College of Speech and Language Therapists, 2003; Speech Pathology Association of Australia, 2005). Healthcare facilities in ROI do not post placement opportunities as they do in the United States (ASHA, 2021). As a group, we have long recognized that this approach to securing placements is labour intensive, involves unnecessary duplication, is not fit for purpose, and leads to unnecessary competition. While in the past, attempts have been made to streamline the process, this never materialised in practice until this year. SLTs are not unique in our approach, as all our allied healthcare colleagues organize placements individually by university in the ROI.

In 2020, the added impact of the COVID-19 pandemic made it highly likely there would not be enough placements. A survey completed by our professional body, the Irish Association of Speech and Language Therapists (IASLT), indicated that $47 \%$ of therapists were redeployed as a result of COVID-19, leading to widespread disruption or suspension of SLT services, cancellation of over 70,000 SLT appointments, and increases in work absences (Cullen, 2020; IASLT, 2020b). Universities, including their on-site clinics, shut their doors abruptly and moved to online teaching. This perfect storm led to our SLT student placements being shortened, cancelled or postponed.

\section{Stage 2: Feelings}

It was clear to us as PECs at the centre of the problem, that significant difficulties were in store for the academic year 2020-2021, which led to feelings of' worry, uncertainty, and frustration. For example, worry that this would have a knock-on effect on students' ability to progress to the next year and/or graduate within the expected timeframe. Also, frustration that many of the sudden changes were out of our hands, and therefore more difficult to mitigate.

\section{Stage 3: Evaluation}

In light of the former feelings and the context we found ourselves in, it was decided that an urgent intervention was required. We were empowered to prioritize collaboration and attempt to problem solve as a profession rather than at our respective university level.

We evaluated the available evidence from national and international sources in search of possible solutions. We weighed up the potential benefits of new approaches being adopted in nearby Scotland and Northern England where they had developed centralized approaches to securing placements. Based on these collective evaluations, we developed a new, single nationwide structure to facilitate healthcare and educational settings to offer placements in the context of COVID-19. We labelled this structure the 'National Placement Call'.

Our primary motivation was to secure placements by creating something we believed was more informative and more accessible for SLTs. We also believed the data would prove powerful in our campaign to highlight the difficulties to senior managers. Using an online form, the National Placement Call enabled a one-stop-shop of placement details and a facility to provide placement offers for any of the four universities. It was distributed widely in August 2020 to all SLTs in the ROI via email, twitter and IASLT mailing lists, followed by four fortnightly reminders and was accompanied by a guidance 
document for clinical supervisors on how to deliver a blended approach to placements in the context of COVID-19 (IASLT, 2020a).

\section{Stage 4: Analysis}

Ninety-four placement offers were received, representing $19.5 \%$ of those needed. The majority of placement offers were in primary care services for children (38\%), followed by disability settings (27\%), primary care services for adults (19\%) and acute hospital settings (16\%). Placement offers were unevenly distributed across the four universities, ranging from a share of $13 \%$ to $32 \%$.

In addition to analysing the quantitative data, we reflected together through regular online meetings on the process of the National Placement Call, and the implications for the future. First, this initiative identified periods in the academic year of significant demand for placements and other times when there was no demand. Second, the National Call provided a powerful springboard to draw the attention of our university management teams and government bodies regarding the intensifying crisis of placement shortages. This timely sharing of data achieved some traction, highlighting the fact that we needed support from all stakeholders involved in clinical education. Third, working together in this manner presented the four universities as a united front to the profession for the first time and added weight to the argument that alternative means of sourcing placements and providing clinical education are required as a matter of some urgency. Fourth, this collaboration allowed for additional opportunities to share learning amongst ourselves for alternative avenues to support clinical competency development, such as supporting telehealth and simulation learning experiences. Fifth, this initiative led to the creation of a national forum, which consists of PECs and Head of Departments, facilitating discussion and information sharing on SLT practice placement issues nationally and providing support and a route for escalating concerns to relevant authorities. Sixth, on reflection, although we believed we were working together at the time, we were still not sufficiently acting as one unit. The National Placement Call still reflected independent university identities, which can be seen in the different approaches to student support, clinical examinations and durations of placements that CEs must grapple with.

\section{Stage 5: Conclusion}

While the National Placement Call resulted in a diverse spread of placement offers, it met less than $20 \%$ of requirements. However, this tool has finally provided us with a very detailed national picture of placement provision across the country and several associated benefits. Our understanding of the significant step we had taken became clearer in the months after the launch through the informal feedback we received about the benefits of the call and ways it could be improved. Future iterations will incorporate this input and be reflected in our action plan. In addition, our initiative is being closely monitored by our colleagues in other professions, some of whom plan to make the bold transition to collaborative working that we are proving has potential.

\section{Stage 6: Action plan}

There are a number of actions we plan to implement. The National Placement Call was a static list of placement needs, but we now believe due to the impact of COVID-19 perhaps a more flexible and dynamic call would have been more suitable to respond to sudden changes in universities' requirements and alterations to SLT service capacity issues. This flexibility will be incorporated into future iterations. One avenue of inquiry that was initially omitted was an opportunity for SLTs to give formal feedback on what the enablers and barriers were to offering placements, which will be included in future calls to support revisions and improvements. Further analysis and evaluation of the numbers, types and geographical spread of placement offers may help maximize placement offers through providing targeted supports to areas of low engagement. We will seek greater technical, financial and administrative support to fine-tune the tool used to gather placement offers and analyse the subsequent data collected (e.g., enable live updates on placement offers received and current shortages).

\section{Conclusions}

Placements expose students to a range of crucial, dynamic clinical experiences that are not always possible to achieve in the structured, predictable learning context of the classroom (Deasy et al. 2016). Therefore, having a sustainable means of securing sufficient placements is fundamental for the future of the SLT profession. Working collaboratively with other national universities is one step to ensure a 
greater supply of placements, but greater organisational, professional, structural and systemic changes are required for a long-term solution. As the Irish proverb states:

Ní neart go cur le chéile (there's no strength without unity).

\title{
Acknowledgements
}

The authors would like to thank all of our Speech and Language Therapy colleagues who answered the National Placement Call.

\section{ORCID}

Kerrie O'Grady:

Laura Loftus:

Duana Quigley:

\author{
https://orcid.org/0000-0002-9586-4842 \\ https://orcid.org/0000-0002-3554-2489 \\ https://orcid.org/0000-0003-4012-0165
}

\section{References}

ASHA. (2021). Student externships. https://www.asha.org/Students/Externships/

Bourne, E., McAllister, L., Nagarajan, S., \& Short, K. (2019). The effect of speech-language pathology students on clinician time use and activity. International Journal of Speech-Language Pathology, 21, 163-174. https://doi.org/10.1080/17549507.2017.1416175

Cullen, P. (2020, December 3). Almost 300,000 essential therapy appointments missed in first half of year. The Irish Times. https://www.irishtimes.com/news/health/almost-300-000-essentialtherapy-appointments-missed-in-first-half-of-year-1.4425897

Deasy, C., Coughlan, B., Pironom, J., Jourdan, D., \& McNamara, P. (2016). Psychological distress and help seeking amongst higher education students: findings from a mixed method study of undergraduate nursing/midwifery and teacher education students in Ireland. Irish Educational Studies, 35, 175-194. https://doi.org/10.1080/03323315.2016.1146157

Gibbs, G. (1998). Learning by doing: A guide to teaching and learning methods. Further Education Unit. https://houghtsmostlyaboutlearning.files.wordpress.com/2015/12/learning-by-doing-grahamgibbs.pdf

IASLT. (2020a). Supporting student speech and language therapy placements in the context of COVID19: A practice educator guide to a blended approach. https://www.iaslt.ie

IASLT. (2020b). The Irish Association of Speech and Language Therapists pre-budget submission 2021. https://www.iaslt.ie/documents/public-information/IASLT/IASLT_Pre-Budget\%202021.pdf

McAllister, S., \& Nagarajan, S. (2015). Accreditation requirements in allied health education: Strengths, weaknesses and missed opportunities. Journal of Teaching and Learning for Graduate Employability, 6, 2-23. https://doi.org/10.21153/jtlge2015vol6no1art570

Quigley, D., Loftus, L., McGuire, A., \& O’Grady, K. (2020). An optimal environment for placement learning: Listening to the voices of speech and language therapy students. International Journal of Language and Communication Disorders, 55, 506-519. https://doi.org/10.1111/1460$\underline{6984.12533}$

Royal College of Speech and Language Therapists. (2003). Position paper: The provision of clinical placements: Stakeholder roles \& responsibilities. https://rcslt.org/wpcontent/uploads/media/Project/RCSLT/positionpaperclinicalpdf.pdf

Speech Pathology Association of Australia. (2005). Position statement. Clinical education: The importance and value for the speech pathology profession. https://www.ndp.org.au/images/NDP_Navigation/NewToSector/Position_Statement_ClinicalEducation.pdf 